\title{
The Cultivation of Outstanding Engineers on the Background of
}

\author{
"Industrial 4.0" \\ Hui Zhang ${ }^{1, a}$, Hong Yin ${ }^{2, b^{*}}$ \\ ${ }^{1}$ Academic Affairs Department, Hefei University of Technology, Hefei 230009,China. \\ ${ }^{2}$ School of Electronic Science and Applied Fhysics, Hefei University of Technology, Hefei \\ 230009, China;

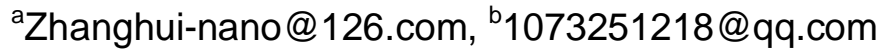

Keywords: Industrial 4.0; engineering education; cultivation of outstanding engineers

Abstract. After German put forward "Industrial 4.0" and the United States put forward the plan of revitalization of manufacture, a wave of transformation and upgrading of manufacture was raised. In order to meet the challenge of the international "Industrial 4.0", China started "Outstanding Plan" in 2010, hoping to cultivate excellent engineering talents and make itself go to engineering power. This paper discussed the influence of "Industrial 4.0" on training outstanding engineers, and put forward the corresponding training countermeasures in terms of enhancing university-enterprise cooperation, teachers and students' improvement on their ability.

\section{Introduction}

"Industrial 4.0" is the fourth industrial revolution on basis of intelligent manufacturing and pushes manufacturing into intelligence by using the Internet of things, informatization and automation to improve the level of manufacturing. It is divided into three themes: intelligent factory, intelligent production, and intelligent logistics. Major developed countries in the world has their own "industrial 4.0" strategic plan. As one of the most competitive manufacturing countries, German "industrial 4.0" gets the most attention in the world. Germany officially launched the German Industrial 4.0 Strategic Plan Implementation Suggestion in Hannover Industry Messe in April 2013, to keep ahead in the new round of industrial revolution and ensure the future of the German manufacturing. As early as in April 2009, the United States has put forward the strategy of reviving American manufacturing, and the strategic policies gradually triggered a discussion about reviving manufacturing in the world. In June of 2014, China put forward the plan of "made in China 2025", which became a roadmap for the future development of "made in China", also known as the Chinese version of "Industrial 4.0". "Industrial 4.0" launched a challenge to traditional higher engineering education. Engineering education of colleges and universities should actively respond to this challenge, by the combination of high-quality teachers, the establishment of modern theories and technology courses, and the cooperation with advanced enterprise, train outstanding engineers who meet the needs of "Industrial 4.0" for the future . 
"Outstanding Engineers Training plan" (referred to "Excellence Plan") aims to push our country into the engineering education power, foster a large number of various engineering and technical talents who adapt to the economic and social development needs and with strong innovation ability. The core and key of "Excellence Plan "is to cultivate students' engineering practice ability and engineering innovation ability. In November 2013, General Standard of Outstanding Engineers Education Training Plan was put forward. General Standard points the basic requirements which all kinds of engineering talents should meet, is a macro guidance to make industry standards and college standards. To some extent, these standards are consistent to the requirements of which "Industrial 4.0" to engineering talents. For example, in order to control the automation of intelligent manufacturing equipment, outstanding engineers must master some professional skills and have some comprehensive abilities, which increases the demand for interdisciplinary talents.

\section{The Present Situation of Domestic and Foreign Outstanding Engineers Training}

German "Industrial 4.0" strategy is carried by government, scientific circles, colleges and universities, and business circles, aims to promote the cross-border cooperation of different industry groups and the transformation and upgrading of industry from manufacture to intelligent manufacturing. Germany pays attention to each close link of industry-university-research cooperation, emphasizes practice process, method training, and ability training, and adheres to the innovation of science and technology. In specialized course teaching, most teaching contents are directly from the production practice, and many of them combine with the newest technology enterprises use. Colleges and universities try to give students an opportunity to enter factories when arranging teaching plan so that students have sufficient hands-on opportunities to contact actual production, and cultivate their ability of engineering practice and engineering innovation.German companies regards the cooperation with colleges to be very important and they are the main body of evaluating college's practice teaching achievements. In response to the form and content of "Industrial 4.0", German and International Industrial Enterprises jointly issued a "college of cube"

initiative , which has 18 classes in the field of "Industrial 4.0", including 6 complete courses and 12 special courses, and the content of them includes large data analysis, manufacturing and logistics process, automation, information security and data protection, etc.

In the plan of manufacturing revitalization, the United States attached great importance to the cultivation of engineering talents. Manufacturing talents training mainly include: (1) In terms of education, school attached great importance to the engineering education and emphasized STEM (science, technology, engineering, and math) education; increased education investment; strengthened the cultivation and training of teachers of science and engineering and practice teaching. In addition to the complete curriculum theoretical study and experiment course assignments, students have about a month to do the experiment or design which they are interested in and in connection with this course. Engineering department uses every summer in studying some companies' actual issues. Many universities in the U.S set up experiment lesson as an independent lesson, even as a core curriculum. (2) At the enterprise level, companies strengthen job training, improve staff's quality and skills and increase the employment rate; improve product technology content, enhance brand awareness; strengthen the research and development cooperation with colleges and universities, and provide convenience and opportunities for college's research and 
students' practice. (3) In manufacturing renaissance strategy, the U.S. Government emphasizes scientific and technological innovation, and consolidate the importance of science and technology innovation base, and brought it into the national strategy of core principles.

China has not really become the main body of technological innovation because of the restriction of the traditional ideas, money. Chinese engineering talents training mode is single, engineering practice is weak, assessment system emphasizes paper but ignores design, industry-university-research cooperation does not reach the designated position, and so on, all of these cause our country engineering talents to be scarce. Thus it can be seen that there is a big gap in manufacturing development level, technology level, innovation ability and industry-university-research cooperation between China and German, U.S. Therefore, China can acquire a lot of experience from the two countries' process of transformation and upgrade of manufacturing to cultivate outstanding engineers.

\section{The Cultivation of Outstanding Engineers}

The cultivation of outstanding engineers both needs the reference of some developed countries and combines with domestic actual situation. Colleges and enterprises, teachers and students are the main core in the cultivation of outstanding engineers, they have their own work and duties in the cultivation process.

The Job of College, University and Enterprise "Industrial 4.0" demands excellent engineers not only have rich theoretical knowledge, but also must have proper engineering practice ability and engineering innovation ability, which requires colleges and enterprises pay attention to the cultivation of student's practical ability, innovation ability, and engineering quality in the process. First of all, Colleges need to establish the strategic status of the outstanding engineers' training, set up outstanding engineer training funds and "outstanding project" committee to encourage teachers to actively participate in the teaching reform of outstanding engineers; strengthen the supervision of outstanding engineer training. Secondly, strengthen the reform of curriculum, teaching material, teaching model and practice teaching. Colleges should change the original teaching model of imparting knowledge, optimize the curriculum structure, increase practice teaching time, realize the organic combination of imparting knowledge and training skills. Under the background of "Industrial 4.0", students need to master some new technologies, such as big data, Internet, mobile Internet and cloud technology. In order to combine the newest teaching theories with actual industry development situation, Tongji University took the lead in setting up introductory theory of "Industrial 4.0" for entire students majoring in science at college, to help young students understand the the latest developments of industrial field. In the way of teaching, colleges carry out case teaching and research learning, strengthen the interaction between teachers and students to increase the fun of knowledge transfer; Colleges need to establish outstanding engineers training laboratory, advocating students' autonomy study and practice research, to provide a certain platform for the cultivation of students' project practice ability and innovative ability.

As the direct recipients of outstanding engineers, enterprises have an obligation to participate in the cultivation of engineering talents. Enterprises should participate in the construction of teaching plan, training standards, teaching material, practice base and examinations on outstanding engineers 
together. Enterprises should make efforts to promote "industry-university-institute" cooperation, participate in the running process, and test running results. According to the requirements and the training objectives of colleges, enterprises make the talent training scheme, provide students with mentors, help students determine the research direction and guide the students' learning and practice; put companies' engineering problems into the teaching material for students and teachers to study and research. Enterprises and colleges set up practice base for students, make students apply theory knowledge into actual production practice better, solve the disconnect contradictions of engineering education theories and the actual problems. In addition to achieving universal basic professional standards and industry standards, enterprise should also pay attention to students' sense of social responsibility and engineering ethics; the skills of active learning and communication skills; the training of ability to adapt, team work spirit and bearing hardships and standing hard work.

The Job of Teachers and Students The background of "Industrial 4.0" not only have a new request for colleges and universities and enterprises, also puts forward the corresponding requirements for teachers and students and requires teachers and students have a multi-disciplinary comprehensive knowledge background and various abilities. The present problems of engineering teachers are the lack of enterprise practice experience, weak practice ability, and the lack of part-time teachers and so on. Teachers should strive to enrich their own enterprise practice experience, improve their practice ability. Teachers should go to production line, undertake the scientific research project of the enterprise, timely grasp the latest technology of the enterprise, and put the engineering practice closely embedded in the teaching process.

The key of outstanding engineers is in the cultivation of students themselves. Students should make efforts to improve their engineering innovation consciousness, the ability of engineering practice and the attitude of pursuit of excellence, as well as enhance the professional ethics and social responsibility. First of all, students should strive to improve their engineering practice ability and innovation ability. Through the implementation of the college students' innovative projects, students can organize a team to discuss solutions, it can cultivate the team's cooperation ability and practice ability; By referring literature and investigating, it can train their own thinking ability. In extra-curricular science and technology activities, students can enjoy the pleasure of innovation and subject contest, stimulate initiative and creativity, and realize the full development of personality. Secondly, students should also improve their humanistic quality, not only be limited to their professional knowledge, but also dabble in some humanistic knowledge. It can broaden their horizons, make themselves have a certain international vision and ability of competition and cooperation under the cross-cultural communication environment. Most importantly, students should understand the latest information of "Industrial 4.0" and the current development trend in industrial field, in time to enrich their own knowledge view, as well as set up the idea of innovation, cooperation, development and service firmly.

\section{Conclusion}

In order to meet the challenge of "Industrial 4.0", Chinese cultivation of outstanding engineers must combine its own training standards and some advanced manufacturing countries' engineering talents training mode. Only in this way can China walk out a road of engineering talents cultivation with its own characteristics. On the one hand, the training mode combines the German-American good ways, such as increasing education investment, strengthening the 
manufacture-learning-research cooperation, constructing innovation drive system, etc, also accord with its own standards, such as cultivating the attitude of pursuing excellence, innovative consciousness, international version, and the basic ability of competition and cooperation under the cross-cultural communication environment. On the other hand, combing with the international background of "Industrial 4.0" to cultivate outstanding engineers can test outstanding engineers' training qualities to see if it can achieve outstanding engineers' universal standard, and put China into the age of "Industrial 4.0". In short, the cultivation of outstanding engineers must conform to the requirements of the background of "Industrial 4.0", China can catch up with the international trend and cultivate high -quality outstanding engineers.

\section{Acknowledgements}

The research is supported partly by the Key Teaching Research Project in Anhui Province (No.2012 jyxm 025) and mainly by the National Education Reform Pilot Project (No.01-236-335).

\section{References}

[1] Zhengchu He, Hongyu Pan, German "Industrial 4.0 "and" made in China 2025"(in Chinese), Journal of Changsha University of Science and Technology (social science edition), 2015, (3), pp.103-110.

[2] Dongmei Yuan, The challenge of U.S. manufacturing to revive on the talent reserve (in Chinese), International Trade Issues, 2012,(4), pp.49-58.

[3] Jianqiang Liu, The enlightenment of the mode of German University of applied sciences on the implementation of the "Outstanding Engineers Training Plan"(in Chinese), China Higher Education Research, 2010, (6), pp.50-52.

[4] Jin Wen, Innovation education- oriented outstanding engineer training mode (in Chinese), China Education Innovation Herald, 2011, (22), pp.12-14.

[5] Carl Ernst Fesch, New development of the university of applied sciences in Germany, Beijing, 2008, Higher Education Press.

[6] China needs "Industrial 4.0", more need to promote the training of "Industrial 4.0" talents on www.whichmba.net/business.do?actionId=BrowseArticle \&channel=0\&Id=1134 